\title{
Inflorescência terminal da bananeira em dois Atlas Linguísticos brasileiros: um estudo comparativo
}

\author{
Terminal de inflorescencia del árbol de plátano en dos atlas lingüísticos \\ brasileños: un estudio comparativo
}
Terminal inflorescence of the banana tree in two brazilian linguistic atlas: a comparative study

\author{
Marcelo Pires Dias 1 \\ Marilucia Barros de Oliveira ${ }^{2}$
}

\begin{abstract}
Resumo
Trata o presente artigo da diversidade lexical a partir de dados do Atlas Geossociolinguístico Quilombola do Nordeste do Pará (AGQUINPA) e do Atlas Linguístico do Brasil (ALiB). Trata-se de um estudo comparativo que tomou como base as respostas mapeadas nos dois atlas referidos para a questão 44 do Questionário Semântico-lexical do ALiB. O ALiB registrou respostas obtidas nas capitais brasileiras e considerou dois níveis de ensino: fundamental e superior. Já o AGQUINPA registrou a diversidade lexical em seis comunidades quilombolas localizadas no Nordeste Paraense e considerou apenas o ensino fundamental. Os resultados apresentados nos dois atlas mostram número alto de variantes para a referida questão a depender da região e apresentam diferenças e semelhanças entre a variedade usada nas capitais brasileiras e nas comunidades quilombolas paraenses.
\end{abstract}

Palavras-chave: Atlas Linguísticos; Comunidades quilombolas; ALiB; AGQUINPA; Variação lexical.

\section{Resumen}

Este artículo trata sobre la diversidad léxica basada en datos del Atlas Geosociolingüístico de Quilombola do Nordeste do Pará (AGQUINPA) y el Atlas Lingüístico do Brasil (ALiB). Este es un estudio comparativo basado en las respuestas mapeadas en los dos atlas referidos a la pregunta 44 del cuestionario semántico léxico pertenenciente al ALiB. El ALiB registró las respuestas obtenidas en las capitales brasileñas y consideró dos niveles de educación: fundamental y superior. AGQUINPA registró la diversidad léxica en seis comunidades quilombolas ubicadas en el noreste de Paraense y considerada solo como educación primaria. Los resultados presentados en los dos atlas muestran un gran número de variantes para esta pregunta según la región y presentan diferencias y similitudes entre la variedad utilizada en las capitales brasileñas y en las comunidades quilombolas de Pará.

Palabras claves: Atlas Lingüísticos; ALiB; AGQUINPA; Comunidades quilombolas; Variación léxica;

\footnotetext{
${ }^{1}$ Doutor em Linguística; Faculdade de Etnodiversidade, Universidade Federal do Pará (Campus Universitário de Altamira); Altamira, Pará, Brasil; mpdias@ufpa.br.

2 Doutora em Linguística; Faculdade de Letras, Universidade Federal do Pará; Belém, Pará, Brasil; mariluci@ufpa.br.
} 


\begin{abstract}
This article deals with lexical diversity based on data from the Brazilian Linguistic Atlas (ALiB) and the Geosociolinguistic Quilombola Atlas of the Northeast of Pará (AGQUINPA). It is a comparative study based on the two reference atlases for question 44 of the $\mathrm{ALiB}$ semantic-lexical questionnaire. The ALiB recorded the responses from the Brazilian capitals and considered two levels of education: fundamental and superior. The AGQUINPA, on the other hand, registered lexical diversity in six quilombola (maroon) communities in the Northeast of Pará and considered only elementary education. The results from the two atlases show a high number of variants for the subject in question depending on the region and show distances and approximations between the variant used in the Brazilian capitals and in the quilombola communities of Pará.
\end{abstract}

Keywords: ALiB; AGQUINPA; Quilombola communities; Linguistic Atlas; Lexical variation.

\title{
1. Introdução
}

Ao longo da segunda metade do século XX os estudos da linguagem no Brasil receberam um exponencial interesse no que se refere ao registro das peculiaridades dos falares de Norte a Sul do país, especialmente com os trabalhos de cunho dialetológico de Amaral (1920), Marroquim (1934) e Nascentes (1953), dentre outros, pioneiros no campo da dialetologia brasileira. Na ocasião, era urgente registrar e estudar o fenômeno da variação que abrangia desde aspectos fonético-fonológicos, lexicais, passando, em alguns casos, à exploração de aspectos morfossintáticos

A variação lexical apresenta um excelente mecanismo para observarmos particularidades de certa região, estado ou mesmo países, pois dados dessa natureza podem nos indicar pistas de fluxos migratórios, origens de determinadas comunidades, assim como refazer a trajetória sócio-histórica de uma variedade, bem como possibilita apontar mudanças ocorridas nas comunidades de fala investigadas.

Décadas depois da discussão sobre a necessidade de se construir um atlas nacional, o projeto Atlas Linguístico do Brasil ${ }^{3}$ conseguiu implementar um mega projeto que tem em vista o mapeamento da diversidade e variação linguísticas do Brasil. Esse projeto, já muito desafiador e extenso, não levou em consideração, obviamente, o estudo das variedades usadas em comunidades tradicionais brasileiras como indígenas, quilombolas, por exemplo, ficando essa tarefa para pesquisas mais localizadas. Assim, com o intuito de descrever e mapear as variedades existentes nos espaços não alcançados pelo $\mathrm{ALiB}$, alguns pesquisadores se dedicaram ao estudo da diversidade linguística em comunidades tradicionais. No que tange às comunidades afro-brasileiras $^{4}$, podemos citar alguns pesquisadores que estudaram a variedade usadas nessas comunidades, como o de Lucchesi (2009), Castro (2005), Petter (2009),

\footnotetext{
${ }^{3}$ Para mais detalhes sobre o projeto, consultar www.alib.ufba.br

${ }^{4} \mathrm{O}$ termo afro-brasileiro é mais abrangente. Uma comunidade pode ser afro-brasileira, mas não ser considerada ou não se considerar quilombola. Todas as comunidades no AGQUINPA são consideradas quilombolas.
} 
Oliveira (2010). Há outros que se ativeram especificamente ao estudo dialetológico dessas comunidades, afim de descrever e mapear a diversidade encontrada nelas. Na região Norte, deu-se destaque para as comunidades indígenas e quilombolas. São exemplos desses trabalhos: Dias (2017), Sá (2018), Costa (2019) $)^{5}$, Costa (Tese em andamento), Guedes (2017), Costa (2019), Rodrigues (2017) e Alves (2019). Os quatro primeiros trabalhos dedicaram-se ao estudo em comunidades afro-brasileiras; já os quatro últimos abordaram a diversidade linguística em comunidades indígenas.

Essas pesquisas permitem um conhecimento mais localizado e abrangente da diversidade linguística brasileira. Também podem apontar em que medida as variedades usadas por essas comunidades tradicionais se aproximam ou se distanciam das variedades usadas em falares urbanos, rurbanos e rurais. No sentido de identificar possíveis semelhanças e diferenças entre esses espaços, propomo-nos a cotejar resultados encontrados em comunidades quilombolas com os registrados nas capitais brasileiras Trata-se de comparar os resultados encontrados no AGQUINPA aos do ALiB.

O Atlas Geossociolinguístico Quilombola do Nordeste do Pará (AGQUINPA) é um atlas de pequeno domínio que mapeou seis comunidades quilombolas distribuídas na mesorregião Nordeste do Pará, área que possui considerável número de comunidades quilombolas, o que também motivou a escolha da referida região. A descrição linguística do léxico em comunidades quilombolas é importante não somente pelo fato de essas comunidades fazerem parte da população com pertencimento tradicional, mas também por serem o lócus da variedade rural do português brasileiro. Gomes (1999) ressalta que alguns quilombos ou mocambos acabaram tomando a configuração de comunidades camponesas na Amazônia.

O ALIB quase dispensa apresentações para o público brasileiro da área. É um atlas Linguístico que mapeou 250 localidades de Norte a Sul do País, a partir de questionários aplicados a 1.100 informantes estratificados. A escolha dessas localidades levou em consideração, além de outros critérios, as sugestões de Antenor Nascentes, célebre pesquisador conhecido pela proposta de divisão dialetal do Brasil e autor da obra Bases para a elaboração do Atlas Linguístico do Brasil (1958). Em 2014 foram publicados dois fascículos do ALiB. No segundo fascículo estão registradas a variedade lexical e a variação fonética com base nos dados oriundos de coleta de dados nas capitais brasileiras.

\footnotetext{
${ }^{5} \mathrm{O}$ estudo de Costa (2019) difere dos demais trabalhos citados, pois o mapeamento é apenas um meio para a autora discutir territorialização linguística e apontar variantes linguísticas representativas de territorialização.
} 
Tomando como base a questão $\mathrm{n}^{\mathrm{o}} 44$ do Questionário Semântico-lexical (QSL) pertencente ao conjunto de questionários do Atlas Linguístico do Brasil, utilizado também no AGQUINPA, que contém a seguinte pergunta “...ponta roxa no cacho da bananeira?", apresentaremos as variantes registradas em ambos os atlas e discutiremos a distribuição e a representatividade das respostas registradas tanto no âmbito especifico das comunidades quilombolas quanto no escopo da realidade linguística do Brasil retratada no ALiB.

Nas próximas seções, faremos uma breve apresentação das comunidades quilombolas cujos dados integram o corpus deste estudo, com destaque para os aspectos que serão explorados na seção em que apresentaremos e discutiremos os resultados. Em seguida, descreveremos a metodologia que adotamos para tratamento dos dados. Por fim, apresentaremos os resultados presentes nos dois atlas, bem como faremos a comparação entre os resultados registrados.

\section{2. $O$ contexto da pesquisa}

A formação das comunidades quilombolas passou a ocorrer bem antes do fim oficial da escravidão no Brasil e tem como origem as constantes fugas de negros escravizados, que fugiam dos castigos físicos e da precária condição a que eram submetidos. Para dificultar a recaptura, esses negros fugidos acabavam por formar acampamentos provisórios em áreas distantes e que tivessem a proteção natural das matas e barreiras físicas como montanhas e rios.

No Pará colonial do século XIX, os quilombos foram formados também a partir de fugas, com a diferença de que, em alguns casos, a área escolhida tinha proximidade de comunidades indígenas, o que facilitava a sobrevivência e dificultava o trabalho das expedições de recaptura. Também tivemos casos em que a área na qual se situava determinado quilombo fazia parte dos antigos engenhos de cana de açúcar que foram abandonados após a crise que afetou o setor. Os negros escravizados que eram utilizados no empreendimento acabaram por ocupar aquelas terras, como no caso das comunidades quilombolas situadas em São Domingos do Capim, no sítio arqueológico do Aproaga, no Rio Capim (MORAES, 2012).

As seis comunidades quilombolas que integram o AGQUINPA passaram por um longo e burocrático processo de reconhecimento que culmina com a titulação efetuada pelo 
INCRA. É importante destacar que antes do processo formal de reconhecimento e titulação, a comunidade precisa de autorrecohecimento.

Atualmente, o Brasil possui mais de 3.000 comunidades quilombolas; 2.197 são reconhecidas e apenas 206 possuem o título definitivo emitido pelo INCRA. A maioria dessas comunidades quilombolas encontram-se em áreas rurais de difícil acesso, com infraestrutura precária. Com a titulação essas comunidades podem se proteger juridicamente das ameaças dos empreendimentos agrícolas que utilizam áreas adjacentes aos quilombos. Nas comunidades quilombolas do Nordeste do Pará, os principais problemas encontrados são: expansão da fronteira agrícola para o interior das terras quilombolas, contaminação dos rios por agrotóxicos utilizados pela indústria do dendê, desmatamento ilegal e extração ilegal de palmito.

Considerando este contexto, decidimos realizar a coleta de dados e a posterior descrição do léxico de comunidades quilombolas do Nordeste do Pará por entendermos que esta variedade do português brasileiro rural ainda necessita ser descrita. Na próxima seção, detalharemos a metodologia utilizada neste estudo, assim como as informações referentes à cartografia dos dois atlas aqui estudados.

\section{Metodologia}

O presente artigo toma por base resultados registrados em dois atlas publicados no Brasil, o AGQUINPA e o ALiB, com o objetivo de comparar e discutir os resultados diatópicos neles registrados para a questão 44 do QSL.

Os dois atlas comparados neste trabalho seguem diretrizes comuns, de modo que o Atlas Linguístico do Brasil serviu de modelo para o AGQUINPA, especialmente no que diz respeito aos procedimentos para coleta de dados e questionários utilizados, pois ambos utilizaram o Questionário Semântico-lexical (QSL).

O Atlas Geossociolinguístico Quilombola do Nordeste do Pará (DIAS, 2017) mapeou seis comunidades quilombolas localizadas na região Nordeste do Pará, região de elevado adensamento de comunidades tradicionais. Essas comunidades são formadas por antigos quilombos, sendo sua população descendentes de remanescentes de quilombolas. Grande parte dessas comunidades subsistem do agroextrativismo e da pesca.

Em cada uma das 6 (seis) comunidades (Rio Acaraqui/Campompema; Cacau, América; Taperinha; África e Laranjituba) foram aplicados questionários, dentre os quais o QSL, a informantes estratificados por sexo (masculino e feminino) e faixa etária (18 a 30 e 50 
a 65 anos). Esses informantes foram selecionados conforme os seguintes critérios: ter nascido na comunidade e não ter se afastado dela por período superior a três anos, além de ter a disponibilidade de tempo para as entrevistas. Foram entrevistados 24 falantes, sendo quatro por localidade. Após as gravações, os dados foram transcritos por meio da ferramenta de transcrição ELAN e, em seguida, cartografados por meio do software de georreferenciamento QGIS. Ao final do processo de cartografação foram geradas 153 cartas semântico-lexicais, das quais 136 são caracterizadas como heteroléxicas, pois apresentaram variação considerável e, portanto, foram alvo de descrição.

O Atlas Linguístico do Brasil é a obra de maior escala da Dialetologia brasileira, Envolveu muitos anos de debates acadêmicos e um exaustivo trabalho de treinamento, coleta, transcrição e revisão. Constitui-se um grande empreendimento da linguística brasileira.

Dadas as dimensões continentais do Brasil, a rede de pontos de inquérito alcançou um total de 250 localidades, incluindo capitais (excetuando Palmas e Brasília) e não capitais, ou seja, cidades dos mais variados portes demográficos. Os 1.100 informantes estão distribuídos em duas faixas etárias (18 a 30 anos e 50 a 56 anos) e por sexo. Nas capitais são levados em consideração dois níveis de ensino: fundamental e superior. Nas não-capitais considera-se apenas o ensino fundamental

Atualmente, dois volumes do ALiB já se encontram publicados, a saber: volume 1 (introdução) e volume 2 (cartas linguísticas). É importante destacar que além dos volumes do atlas há outros trabalhos descritivos oriundos dos dados do Projeto ALiB que vão desde artigos científicos e monografias até dissertações e teses, trabalhos que tratam de aspectos fonético-fonológicos, semânticos-lexicais e morfossintáticos.

Para este artigo utilizamos como ponto de comparação das variantes as cartas referentes ao item lexical inflorescência da bananeira, oriundas da questão QSL n ${ }^{\circ} 44$ (...a ponta roxa no cacho da bananeira?). De um lado tivemos a carta L28 com dados da referida questão no AGQUINPA e no ALiB as cartas por regiões L07a (ALiB/Região Norte), L07b (ALiB/Nordeste), L07c (ALiB/Sudeste), L07d (ALiB/Sul) e L07e (ALiB/Centro-Oeste). Na próxima seção, discorreremos sobre os resultados dessa comparação e apontaremos as similaridades e diferenças entre as variantes registradas nos dois atlas.

\section{Apresentação e discussão dos resultados}


RELACult - Revista Latino-Americana de Estudos em Cultura e Sociedade

Revista Latinoamericana de Estudios en Cultura y Sociedad | Latin American Journal of Studies in Culture and Society V. 05, $\mathrm{n}^{\circ}$ 02, abr-ago., 2019, artigo n' 1642 | claec.org/relacult | e-ISSN: 2525-7870

Os dados registrados em ambos os atlas apresentaram diferenças importantes, pois no âmbito da carta L28 do AGQUINPA, predominou a variante pendão e, em segundo lugar, tivemos a variante mangará, conforme se pode visualizar na carta seguir:

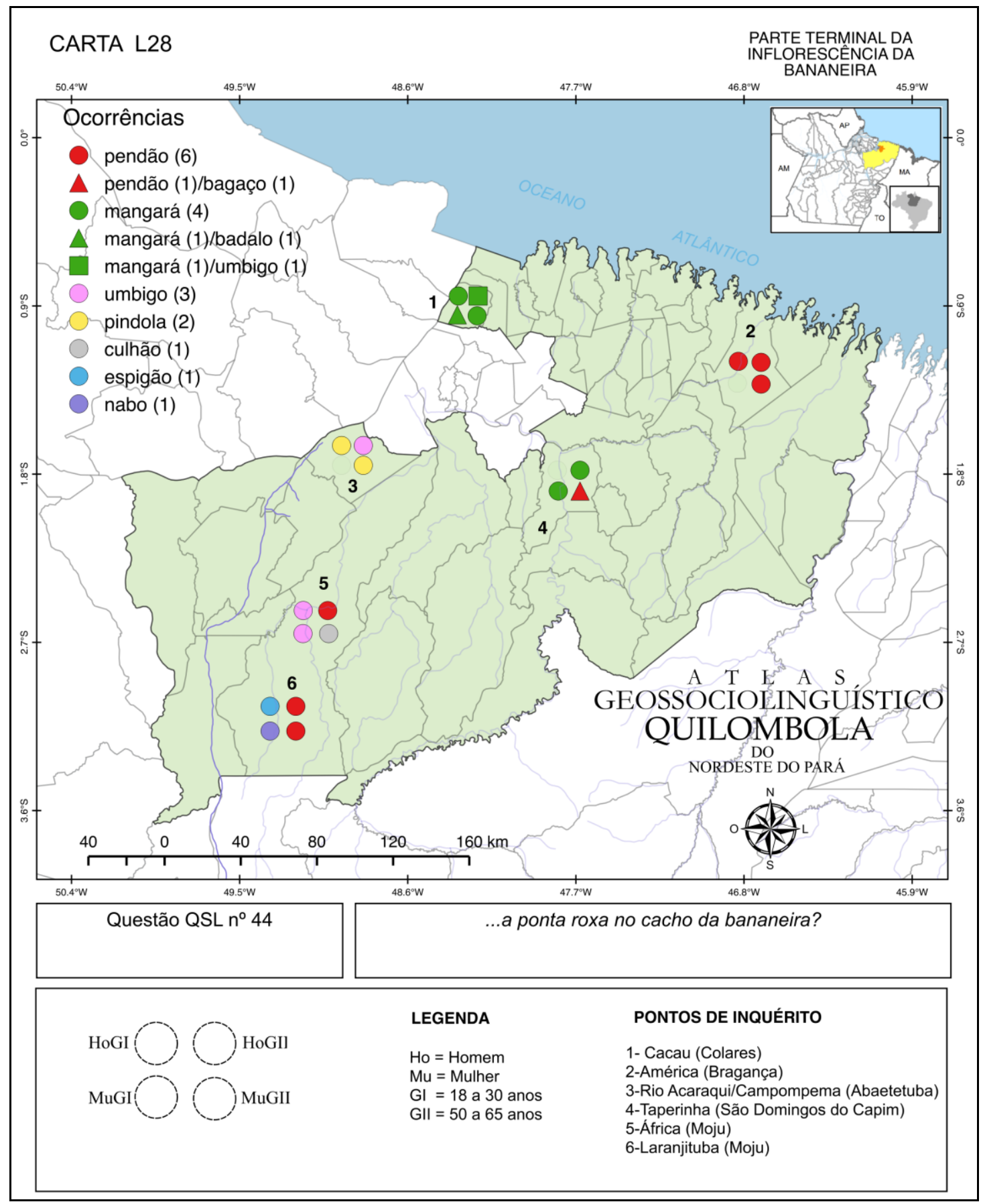

Figura 01: carta L28 do AGQUINPA, referente às denominação para a "parte terminal da inflorescência da bananeira".

Fonte: Dias (2017) 
A carta L07 do ALiB apresenta a distribuição da variante em apreciação nas capitais brasileiras. Como é possível observar, entre as capitais, predomina a variante mangará. Vejamos a carta (Figura 2):

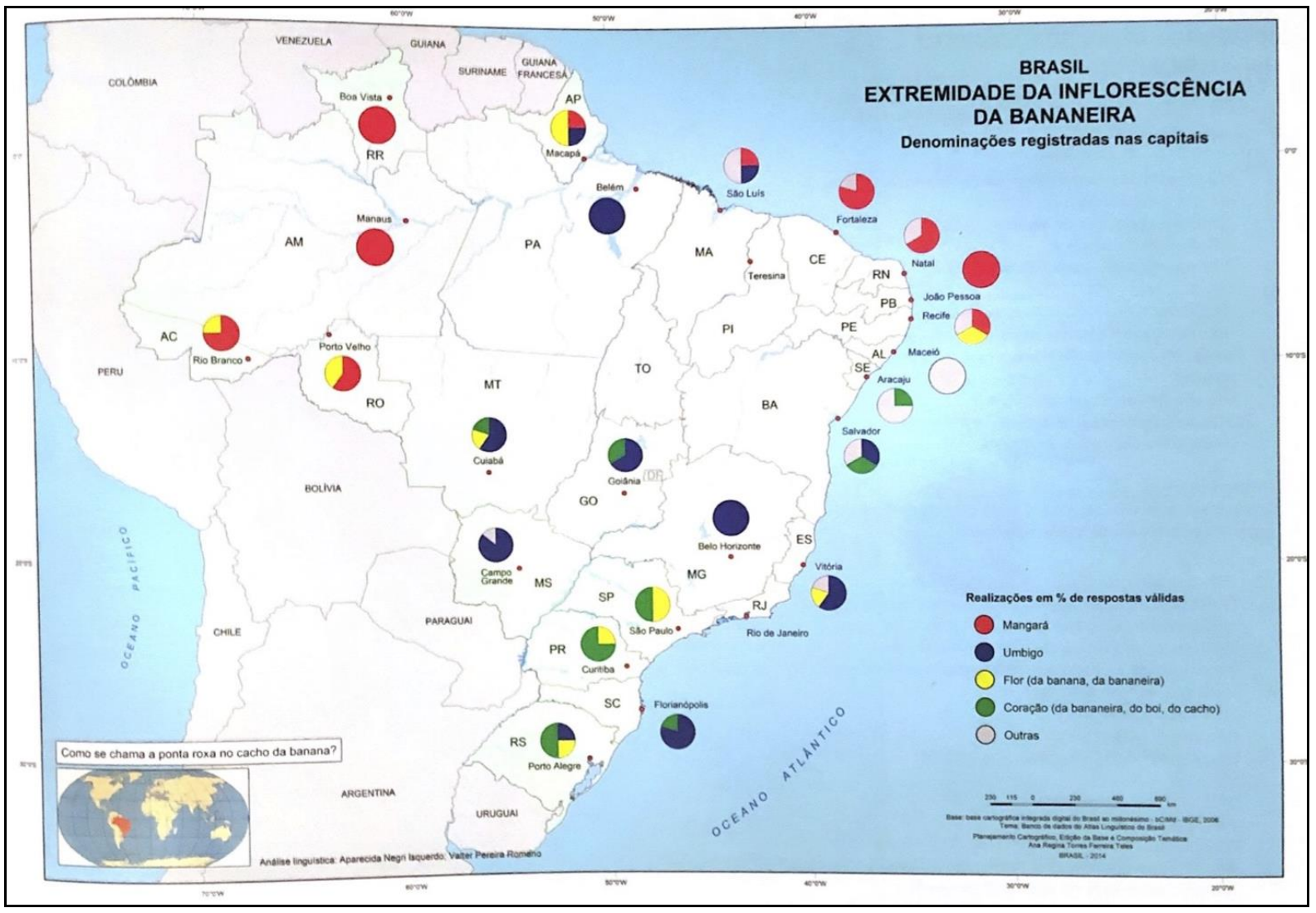

Figura 02: carta L07 do ALiB, referente às denominações para "extremidade da inflorescência da bananeira".

Fonte: ALiB/Cardoso et al (2014)

No ALiB, nas cartas L07a (Região Norte) e L07b (Região Nordeste) predominou a variante mangará. Nas regiões Centro-Oeste (L07e) e Sudeste (L07c) predominou umbigo, enquanto que na Região Sul predominou a variante coração de boi, cujo uso deve estar relacionado à tradição pecuária que existe nessa região.

O quadro 1 apresenta a sistematização dos resultados apresentados nas cartas de acordo com sua frequência decrescente de ocorrência: 
Quadro 1: variantes registradas no ALiB (por regiões) e AGQUINPA (por localidade)

\begin{tabular}{|c|c|c|c|c|c|c|c|}
\hline & $\begin{array}{c}\text { ALiB } \\
\text { (Norte) } \\
\text { Carta } \\
\text { L07a } \\
\end{array}$ & $\begin{array}{c}\text { ALiB } \\
\text { (Nordeste) } \\
\text { CARTA L07b }\end{array}$ & $\begin{array}{c}\text { ALiB } \\
\text { (Centro-Oeste) } \\
\text { Carta L07e }\end{array}$ & $\begin{array}{c}\text { ALiB } \\
\text { (Sudeste) } \\
\text { Carta L07c }\end{array}$ & $\begin{array}{c}\text { ALiB } \\
\text { (Sul) } \\
\text { Carta L07d }\end{array}$ & $\begin{array}{c}\text { AGQUINPA } \\
\text { Carta L28 }\end{array}$ & $\begin{array}{c}\text { Localidades de } \\
\text { ocorrências de } \\
\text { variantes } \\
\text { AGQUINPA }\end{array}$ \\
\hline $\begin{array}{c}\text { VARIANTE } \\
\text { PREDOMINANTE }\end{array}$ & Mangará & Mangará & Umbigo & Umbigo & $\begin{array}{c}\text { Coração de } \\
\text { boi }\end{array}$ & Pendão & $\begin{array}{l}\text { América; Taperinha; } \\
\text { África e Laranjituba }\end{array}$ \\
\hline $\begin{array}{c}2^{\mathrm{a}} \text { VARIANTE DE } \\
\text { MAIOR } \\
\text { FREQUÊNCIA } \\
\end{array}$ & $\begin{array}{l}\text { Flor da } \\
\text { banana }\end{array}$ & Pendão & $\begin{array}{c}\text { Coração do } \\
\text { cacho }\end{array}$ & $\begin{array}{c}\text { Flor da } \\
\text { bananeira }\end{array}$ & Umbigo & Mangará & Cacau; Taperinha \\
\hline \multirow{7}{*}{$\begin{array}{c}\text { DEMAIS } \\
\text { VARIANTES }\end{array}$} & \multirow[t]{7}{*}{ Umbigo } & \multirow{7}{*}{$\begin{array}{c}\text { Buzo da } \\
\text { bananeira; } \\
\text { Coração da } \\
\text { bananeira; } \\
\text { Flor da } \\
\text { bananeira; } \\
\text { Mangai; } \\
\text { Pêndulo; } \\
\text { Umbigo e } \\
\text { Buzina }\end{array}$} & \multirow{7}{*}{$\begin{array}{l}\text { Flor da banana; } \\
\text { Pêndulo }\end{array}$} & \multirow{7}{*}{$\begin{array}{l}\text { Buzina; } \\
\text { Coração }\end{array}$} & \multirow{7}{*}{$\begin{array}{c}\text { Flor da } \\
\text { bananeira }\end{array}$} & Badalo & Cacau \\
\hline & & & & & & Umbigo & $\begin{array}{c}\text { Cacau; Rio Acaraqui e } \\
\text { Åfrica }\end{array}$ \\
\hline & & & & & & Pindola & Rio Acaraqui \\
\hline & & & & & & Culhão & África \\
\hline & & & & & & Espigão & Laranjituba \\
\hline & & & & & & Nabo & Laranjituba \\
\hline & & & & & & Bagaço & Taperinha \\
\hline
\end{tabular}

Os resultados apontam convergências e divergências entre as variantes predominantes no AGQUINPA e nas cartas do ALiB. Cabe ressaltar também que, no ALiB, é o Nordeste que se mostra mais heteroléxico, inclusive, na mesma proporção que o AGQUINPA.

Das nove variantes registradas no AGQUINPA, oito estão dicionarizadas ${ }^{6}$; apenas a variante pindola não possui dicionarização. Dentre as oito (8) variantes dicionarizadas, apenas mangará tem acepção que coincide com a questão indagada no atlas quilombola (inflorescência da bananeira), enquanto que as demais variantes possuem acepções distintas daquelas respondidas pelos informantes, a saber: pendão (s.m.: pedaço de tecido, geralmente retangular, cuja cor ou combinação de cores ou figuras serve de distintivo; bandeira), badalo (s.m.: peça oscilante que faz soar o sino), umbigo (s.m.: cicatriz arredondada resultante do corte do cordão umbilical), culhão (s.m.: testículo), espigão (s.m.: espiga + ão; peça de ferro ou madeira para se cravar na parede; parte de uma peça que entra no furo de outra), nabo (s.m.: planta da família das crucíferas, de raízes brancas ou arroxeadas comestíveis) e bagaço (s.m.: resíduo de frutos ou de qualquer outra substância que foi espremida). Parece que a

\footnotetext{
${ }^{6}$ Dicionário Priberam da Língua Portuguesa. Disponível em: <http://www.priberam.pt/dlpo/chave> Acessado em 11 de julho de 2019.
} 
maioria das variantes usadas pelos falantes resulta de uma construção metafórica que registra a experiência localizada deles também.

Ainda com relação às variantes registradas no AGQUINPA, cabe frisar que pendão não é apenas a variante mais frequente entre as comunidades, mas é também a que apresenta uma arealização mais abrangente, já que foi identificada em quatro das seis comunidades mapeadas. Só não ocorreu em Cacau e no Rio Acaraqui.

No ALiB não foram registradas as variantes badalo, culhão, pindola, espigão, nabo $e$ bagaço, variantes presentes no AGQUINPA, enquanto que as variantes flor (da banana ou bananeira) e coração (da bananeira, do boi ou do cacho) não foram registradas no atlas quilombola.

A variante mangará, que predominou nas cartas L07 e L07a do ALiB e também foi registrada no AGQUINPA, tem origem na língua tupi e possui a acepção de coração. Para a botânica, a estrutura da bananeira em questão é uma inflorescência masculina ${ }^{7}$, que faz parte do cacho da bananeira, como podemos observar na Figura 03 a seguir:

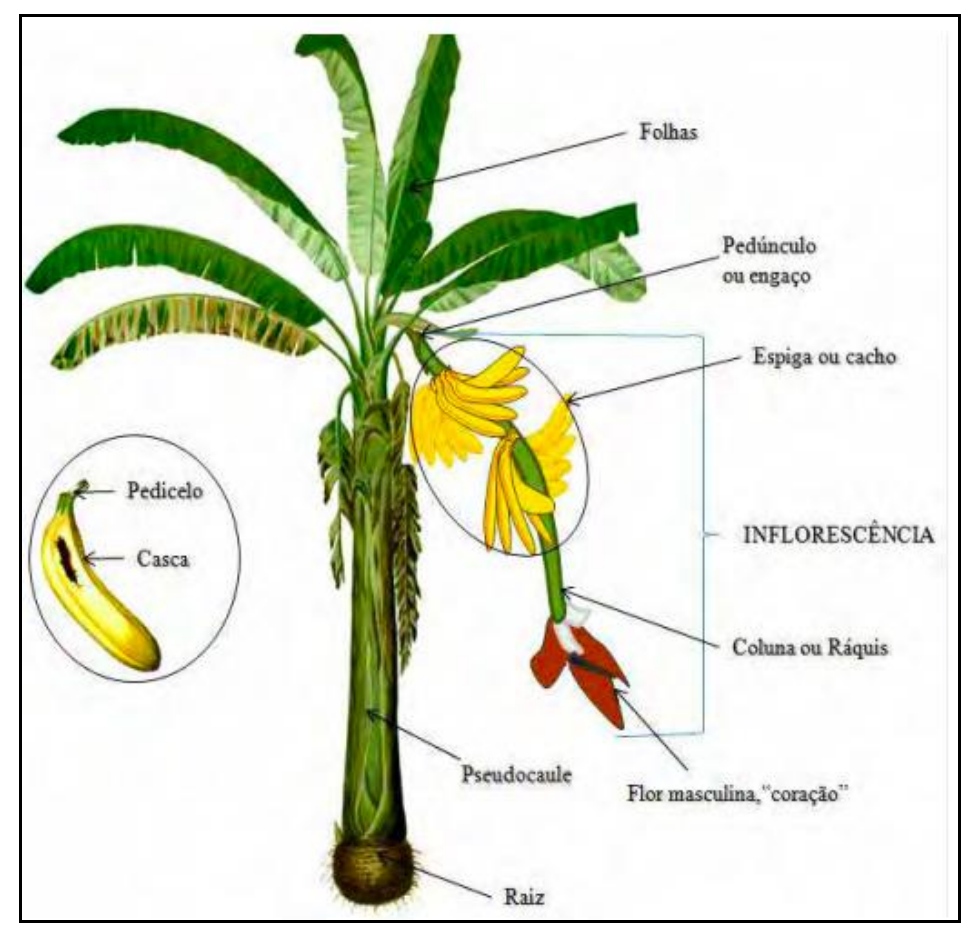

Figura 3: fisiologia da planta de banana (bananeira).

Fonte: IPGRI (2001) apud VILLA VÉLEZ (2011).

\footnotetext{
${ }^{7}$ Talvez daí decorra o uso de culhão como uma das variantes registradas.
} 
Como é possível observar na imagem, a flor masculina presente no cacho da bananeira possui a denominação coração, variante essa registrada no ALiB e "traduzida" do tupi para o português em forma de mangará. Curioso observar que as variantes usadas pelos falantes muito comumente apresentam como estratégia o uso de outras partes do corpo humano para compor as variantes usadas como, por exemplo, coração, umbigo, culhão. Além da presença da denominação coração, também é possível encontrar a variante flor em todas as regiões mapeadas pelo ALiB.

A seguir, apresentamos todas as variantes registradas em dois conjuntos para observamos a intersecção de variantes entre o AGQUINPA e o ALiB.

Imagem 04: intersecção de variantes entre AGQUINPA e ALiB

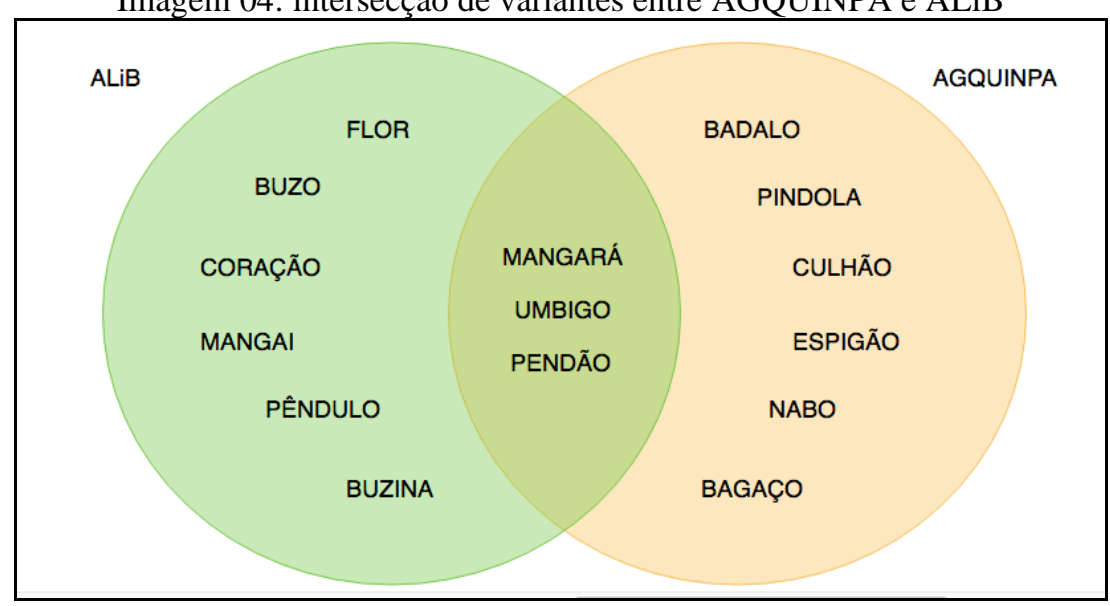

Podemos observar que a interseção entre os dados do ALiB e do AGQUINPA se dá específicamente nas regiões Norte e Nordeste, para mangará e pendão, e com todas as regiões para umbigo. Essa última variante ocorre em todas as regiões, ou seja, impõem-se em todos os espaços avaliados, inclusive o referentes às comunidades quilombolas. Dito isto, parece que as comunidades quilombolas, cujos dados foram aqui avaliados, apresentam uma variedade linguística que se aproxima mais da que é usada na região Nordeste.

\section{Considerações Finais}


No presente artigo, utilizamos resultados lexicais registrados no Atlas Geossolinguístico Quilombola do Nordeste do Pará para a questão 44 do QSL e os comparamos com os apresentados no Atlas Linguístico do Brasil. Eles apontam semelhanças e diferenças no que tange às variantes usadas. Mangará e umbigo são as variantes que se apresentam como mais frequentes em duas regiões cada. Aquela o é no Norte e no Nordeste e umbigo no Centro-Oeste e Sudeste. Essa variante ocorre em todos as capitais e em metade das comunidades quilombolas avaliadas (Cacau, Rio Acaraqui e África). A variedade usada num e noutro atlas mostra que os falantes recorrem a partes do corpo humano para responder à questão em estudo. A forma flor também é bastante utilizada pelos informantes.

Os resultados mostram a ocorrência de seis variantes exclusivas do AGQUINPA; apenas três variantes registradas nesse atlas ocorrem no ALiB. Sobre as semelhanças e diferenças identificadas, temos a dizer que as comunidades quilombolas pesquisadas, embora algumas se localizem distantes dos centros urbanos, têm bastante contato com as zonas rurbanas e urbanas dos municípios em que se localizam. Também têm acesso à midia, o que deve contribuir para essas semelhanças. Ou seja, o contato deve motivar convergências no que se refere ao uso linguístico

Por outro lado, acreditamos que o número alto e exclusivo de variantes encontrado nas comunidades quilombolas deve também ter relação com as atividades sócio-econômicas que desenvolvem. É importante destacar que os quilombolas convivem e lidam diretamente com a diversidade, seja do ponto de vista biológico, social e lingüístico; daí deve advir a pluralidade observada nos nomes que eles atribuem à inflorescência terminal da bananeira, pois essa diversidade linguística reflete o conhecimento tradicional e etnoecológico que eles preservam por meio de sua cultura e modos de vida; reflete sua experiência.

Por fim, ressaltamos a necessidade de empreendermos estudos nessas comunidades não apenas em busca de africanias, cuja ideia ainda permanece muito forte no imaginário de muitos linguistas. É preciso registrar a variedade linguística tal como se apresenta na contemporaneidade dessas comunidades que, inclusive, tiveram de alterar, silenciar determinados traços culturais e usos linguísticos porque considerados bárbaros, conforme assinala Sales (2015).

\section{Referências}

ALIB/CARDOSO, S. A.M. S et al. Atlas Linguístico do Brasil: cartas linguísticas 1. Vol 2. Londrina: EdUEL, 2014. 
ALVES, Fábio Luidy de Oliveira. A variedade do português falado pelos Asuriní do Xingu e pelos Araweté: um estudo geossociolinguístico, 2018. Dissertação (Mestrado) - Universidade Federal do Pará, Instituto de Letras e Comunicação, Belém, 2018. Programa de PósGraduação em Letras.

CASTRO, Yeda Pessoa de. Falares Africanos na Bahia: um vocabulário afro-brasileiro. 2 ed. Rio de Janeiro: TopBooks, 2005.

COSTA, Céliane Sousa. Variação e Territorialização linguísticas: um estudo geolinguístico da diversidade lexical em comunidades quilombolas do Baixo Amazonas, 2019. Tese de Doutorado - Universidade Federal do Pará, Instituto de Letras e Comunicação, Belém, 2019. Programa de Pós-Graduação em Letras.

COSTA, Eliane Oliveira da. Estudo Geossociolinguístico do Léxico do Português falado em Áreas Indígenas de Língua Tupí-Guaraní nos Estados do Pará e Maranhão, 2018. Tese (Doutorado) - Universidade Federal do Pará, Instituto de Letras e Comunicação, Belém, 2017. Programa de Pós-Graduação em Letras.

DIAS, M. P. Atlas Geossociolinguístico Quilombola do Nordeste do Pará, 2017. 2 v. Tese (Doutorado) - Universidade Federal do Pará, Instituto de Letras e Comunicação, Belém, 2017. Programa de Pós-Graduação em Letras. Disponível em: http://repositorio.ufpa.br/jspui/handle/2 Acesso em 4 de junho de 2019.

GOMES, Flávio dos Santos. Fronteiras e Mocambos: o protesto negro na Guiana Francesa. In: GOMES, Flávio dos Santos. Nas terras do cabo Norte: fronteira, colonização e escravidão na Guiana Francesa- séculos XVII/ XIX. Belém, Editora Universitária/UFPA, 1999. pp.225-308.

RODRIGUES, Maria Doraci. Mapeamento lexical do português falado pelo Wajãpi no Estado do Amapá: uma abordagem geossociolinguística. 2017. 151 f. Dissertação (Mestrado) - Universidade Federal do Pará, Instituto de Letras e Comunicação, Belém, 2017. Programa de Pós-Graduação em Letras. Disponível em: <http://repositorio.ufpa.br/jspui/handle/2011/10235>. Acesso em: 4 de junho de 2019.

INTERNATIONAL PLANT GENETIC RESOURCES INSTITUTE (IPGRI). Desciptors for Banana (Musa spp). 2001. Disponível em:

<http://staff.aub.edu.lb/ webeco/ipgri_international.htm>. Acesso em: 23 maio 2019.

LUCCHESI, D.; BAXTER, A.; RIBEIRO, I. (Orgs.). O português afro-brasileiro. Salvador: EDUFBA, 2009.

MORAES, I. P. Do tempo dos Pretos d'antes aos Povos do Aproaga: patrimônio arqueológico e territorialidade quilombola no vale do rio Capim (PA), 2012. Dissertação de Mestrado. Belém: Programa de Pós-Graduação em Antropologia, 2012. 
OLIVEIRA, M. S. D. de; FERNANDES, J. T. V. Aspectos etnolinguísticos da fala em uma comunidade quilombola do Pará: Jurussaca. Cadernos CERU, série 2, v.21, junho de 2010. Disponível em: < http://www.revistas.usp.br/ceru/article/view/11901> Acesso em 4 jun 2019.

PETTER, M. M. T. O continuum afro-brasileiro do português. In: C. GALVES, H. GARMES \& F. R. RIBEIRO. (Orgs.). África-Brasil - caminhos da língua portuguesa. Campinas: EdUnicamp, 2009.

GUEDES, Regis José da Cunha. Perfil geossociolinguístico do português em contato com línguas Tupí-guaraní em áreas indígenas dos estados do Pará e Maranhão. 2017. 295 f. Tese (Doutorado) - Universidade Federal do Pará, Instituto de Letras e Comunicação, Belém, 2017. Programa de Pós-Graduação em Letras. Disponível em: < http://repositorio.ufpa.br:8080/jspui/handle/2011/10536>. Acesso em: 4 de junho de 2019.

SÁ, E. J. de. Atlas Linguístico quilombola do Moxotó-Ipanema Pernambucano (ALQUIMIPE). Relatório de Pós-Doutorado. Belém: Universidade Federal do Pará, 2018.

SALES, Vicente. O negro na formação da sociedade paraense. Belém: Paka-Tatu, 2 edição, 2015.

VILLA VÉLEZ, Harvey Alexander. Aplicações de secagem para o aproveitamento de resíduos da banana, visando sua aplicação na indústria. 2011. 88 f. Dissertação (Mestrado em Engenharia de Alimentos) - Instituto de Biociências, Letras e Ciências Exatas, Universidade Paulista Júlio de Mesquita Filho, São José do Rio Preto, 2011. 